\title{
Animal Models of Alcoholic Liver Disease for Hepatoprotective Activity Evaluation
}

\author{
Hidayah Dwi Renggani ${ }^{1}$, Triana Hertianti ${ }^{2}$, and Retno Murwanti ${ }^{3 *}$ \\ ${ }^{1}$ Master of Pharmaceutical Science Program, Faculty of Pharmacy, Universitas Gadjah Mada, Yogyakarta 55281, Indonesia \\ ${ }^{2}$ Department of Pharmaceutical Biology, Faculty of Pharmacy, Universitas Gadjah Mada, Yogyakarta, 55281, Indonesia \\ ${ }^{3}$ Department of Pharmacology and Clinical Pharmacy, Faculty of Pharmacy, Universitas Gadjah Mada, Yogyakarta, 55281, \\ Indonesia
}

\begin{abstract}
Background: The reported statistics suggest that alcoholic liver disease is on the rise. Furthermore, medications used to treat the disease have unpleasant effects, and this necessitates the need to continuously investigate hepatoprotective agents. This study investigates animal models of alcoholic liver disease used to evaluate hepatoprotective activity. Content: A good number of published articles evaluating hepatoprotective activity were summarized. The studies used three ethanol-induced liver injury models: the acute ethanol-induced liver injury model, the chronic ethanol-induced liver injury model, and LieberDeCarli model. Summary: Wistar rats were primarily used in the ethanol-induced liver injury model. High levels of alanine transaminase (ALT) and aspartate transaminase (AST) and histopathological alterations were found in all animal models (acute ethanol-induced liver injury, chronic ethanol-induced liver injury, and Lieber-DeCarli models). Severe steatosis was shown in both chronic ethanol-induced liver injury and Lieber-DeCarli models. However, fibrosis was undetected in all models. Keywords: Alcoholic liver disease, animal models, hepatoprotective activity, liver injury, ethanol
\end{abstract}

\section{Introduction}

For centuries, alcohol drinking has been a part of social activities in most countries (1). Alcohol use disorders affect millions of individuals worldwide (2). Heavy alcohol consumption is a causal factor for over 60 diseases (3), ranging from simple steatosis to more advanced alcoholic liver diseases, such as steatohepatitis, progressive fibrosis, cirrhosis, and hepatocellular carcinoma $(4,5)$. Alcohol abuse is responsible for $5.3 \%$ (three million deaths) of global deaths (6). A previous study revealed that 75 million people were diagnosed with alcohol use disorders and were at the risk of developing alcohol-associated liver diseases (7). The number of patients with alcoholic liver diseases will continue to increase.

The FDA approved no therapy for alcoholic liver disease $(8,9)$. Bifendate, tiopronin, and potenline are some of the available drugs for the clinical treatment of alcoholic liver diseases (10). While most medications used to treat liver diseases have unpleasant side effects or show limited beneficial effects, such as propylthiouracil, colchicine, corticosteroid, lecithin, and anabolic steroid $(9,11)$, pentoxifylline (PTX) shows improved outcomes for alcoholic liver diseases and reduces the mortality rate $(8,12)$. Nevertheless, side effects such as nausea and vomiting are an obstacle (12), causing lack of adherence. For this purpose, researches on hepatoprotective agents are continuously conducted.
Natural products are one of the major sources of new drug molecules. Many natural products have been traditionally used for the treatment of liver injury (13). Since the last decade, natural hepatoprotection agents have been prominently developed. Silymarin is a wellknown hepatoprotective agent with a high safety profile, derived from Silybum marinum (14).

Animal experiment are still widely used in drug discovery and drug development. For example, pharmacological activity and preclinical studies are evaluated using animal experiments. Preclinical studies are one of the steps of drug discovery and development to ensure its safety and efficacy (15). Many animal models of alcoholic liver disease have been developed. Regarding the excellent conduct of the experiments, information regarding the laboratory animal used and hepatotoxicity induction in laboratory animals from previous study are necessary (16). Therefore, the present study describes the animal models of alcoholic liver disease used for evaluating hepatoprotective activity.

\section{Method}

We searched PubMed using the keyword "alcohol induced hepatotoxicity." The search was performed on January 2021, and conditions were set as follows: "free full text" and "10 years" for the publication date. The search showed 365 articles, which were subjected to screening. Review articles, conference articles, thesis,

\footnotetext{
* Corresponding author: retno_murwanti@ugm.ac.id
} 
and articles without data available to be retrieved were excluded. The inclusion criteria were research articles with in vivo test methods.

\section{Results and Discussion}

Rodents were used in all in vivo alcoholic liver disease models in the publications. Wistar rats were the most frequently used, followed by Sprague-Dawley rats, Kunming mice, and C57BL/6 mice, respectively. Using rodents in the alcoholic liver disease model provides several benefits. Rodents are small in size, have a short life cycle, and offer abundant genetic resources and high numbers of progeny. They are easy to breed and maintain. There are inbred strains, transgenic models, and many knockouts (KO). Moreover, a vast number of commercial immunological reagents are available for rodents $(17,18)$.

In rats, ethanol is metabolized to acetaldehyde by alcohol dehydrogenase (ADH) and aldehyde dehydrogenase $(19,20)$. A sufficient amount of ADH is found in animals, which helps ethanol metabolize faster in animals than humans $(21,22)$. ADH activity in rats is two times higher than that in humans. Thus, this will be the limiting factor in ethanol intoxication study in rats. Normally, rats do not experience alcohol addiction because they will stop consuming alcohol when the acetaldehyde level in the blood is extremely high. However, previous studies demonstrated that rats could display alcohol deprivation effects, and this suggests that their bodies could imitate the human body (23-25).

Besides compiling the articles, we were interested in seeing animals other than rats used in hepatoprotective evaluation models. Large animals have also been used in the models, including baboons and monkeys. Studies on ethanol toxicity in baboons showed that baboons metabolize alcohol similar to humans (53). Other articles stated that if a baboon consumes ethanol at a mild level, ADH isozyme levels could adapt and possibly have a protective effect, similar to humans $(22,54,55)$. Considering that, baboons are probably a good choice in an ethanol-induced liver injury model. Investigation of ethanol toxicity in monkeys showed that $6.2 \pm 0.3$ gram per $\mathrm{kg}$ body weight of oral administration of ethanol displays no signs of hepatotoxicity or fibrosis; therefore, they differ from baboons (56). The higher ethanol metabolism in monkeys might be the reason behind the absence of hepatotoxicity since the same result was reported in another study where monkeys were administered ethanol (57).

Table 1. Summarized data of animal models.

\begin{tabular}{|c|c|c|c|c|c|c|}
\hline No. & Animal used & $\begin{array}{c}\text { Administration } \\
\text { route }\end{array}$ & $\begin{array}{c}\text { Ethanol } \\
\text { concentration }\end{array}$ & Dose & $\begin{array}{c}\text { Duration of } \\
\text { ethanol }\end{array}$ & Ref. \\
\hline \multicolumn{7}{|c|}{ Acute ethanol-induced liver injury model } \\
\hline 1 & Kunming mice & Intraperitoneal & $50 \%$ & $14 \mathrm{~mL} / \mathrm{kg}$ & Once & $(26)$ \\
\hline 2 & $\mathrm{C} 57 \mathrm{BL} / 6$ mice & Oral & $56 \%$ & $13 \mathrm{~g} / \mathrm{kg}$ & 14 days & $(27)$ \\
\hline 3 & Wistar rats & Oral & Not available & $5 \mathrm{~g} / \mathrm{kg}$ & Once & $(28)$ \\
\hline 4 & Sprague-Dawley rats & Oral & Not available & $6 \mathrm{~g} / \mathrm{kg}$ & Once & $(29)$ \\
\hline 5 & C57BL/6 mice & Oral & $50 \%$ & $5 \mathrm{~g} / \mathrm{kg}$ & Once & $(30)$ \\
\hline 6 & Wistar rats & Oral & Not available & $7 \mathrm{~mL} / \mathrm{kg}$ & $\begin{array}{l}5 \text { times every } \\
12 \text { hours }\end{array}$ & (31) \\
\hline 7 & Sprague-Dawley rats & Oral & $56 \%$ & $1.8 \mathrm{~mL} / 100 \mathrm{~g}$ & 2 times & (32) \\
\hline 8 & Kunming mice & Oral & Not available & $5 \mathrm{~g} / \mathrm{kg}$ & $\begin{array}{l}3 \text { times every } \\
12 \text { hours }\end{array}$ & (33) \\
\hline 9 & C57BL/6 mice & Oral & Not available & $6 \mathrm{~g} / \mathrm{kg}$ & Once & (34) \\
\hline 10 & Wistar rats & Oral & $50 \%$ & $12 \mathrm{~mL} / \mathrm{kg}$ & 8 days & (35) \\
\hline 11 & Kunming mice & Oral & $50 \%$ & $12 \mathrm{~mL} / \mathrm{kg}$ & $\begin{array}{l}3 \text { times each } 12 \\
\text { hours }\end{array}$ & (36) \\
\hline 12 & Kunming mice & Oral & $50 \%$ & $10 \mathrm{~mL} / \mathrm{kg}$ & 3 days & (37) \\
\hline \multicolumn{7}{|c|}{ Chronic ethanol-induced liver injury model } \\
\hline 1 & Wistar rats & Intraperitoneal & $15 \%$ & $3 \mathrm{~g} / \mathrm{kg}$ & 15 days & $(38)$ \\
\hline 2 & Wistar rats & Oral & $50 \%$ & $0.5 \mathrm{ml} / 100 \mathrm{~g}$ & 4 weeks & (39) \\
\hline 3 & Wistar rats & Oral & $40 \%$ & $4 \mathrm{~g} / \mathrm{kg}$ & 3 weeks & $(40)$ \\
\hline 4 & Wistar rats & Oral & $56 \%$ & $0.8-1.5 \mathrm{~mL} / 100 \mathrm{~g}$ & 8 weeks & (41) \\
\hline 5 & Wistar rats & Oral & $20 \% \mathrm{w} / \mathrm{v}$ & $5 \mathrm{~g} / \mathrm{kg}$ & 21 days & $(42)$ \\
\hline 6 & Sprague-Dawley rats & Oral & $56 \% \mathrm{v} / \mathrm{v}$ & $10 \mathrm{~mL} / \mathrm{kg}$ & 9 weeks & (43) \\
\hline 7 & Wistar rats & Oral & $28.50 \%$ & $3 \mathrm{ml} / 100 \mathrm{~g}$ & 30 days & (44) \\
\hline 8 & Wistar rats & Oral & $10 \%$ & Not available & 4 weeks & $(45)$ \\
\hline 9 & Wistar rats & Oral & $25 \%$ & $1 \mathrm{ml}$ & 21 days & (46) \\
\hline 10 & Wistar rats & Oral & $70 \%$ & $10 \mathrm{~mL} / \mathrm{kg}$ & 30 days & (47) \\
\hline 11 & Sprague-Dawley rats & Oral & $50 \%$ & $4 \mathrm{~g} / \mathrm{kg}$ & 90 days & (48) \\
\hline 12 & Sprague-Dawley rats & Oral & $50 \%$ & $4 \mathrm{~g} / \mathrm{kg}$ & 90 days & (49) \\
\hline 13 & Wistar rats & Oral & Not available & $3 \mathrm{~g} / \mathrm{kg}$ & 4 weeks & $(50)$ \\
\hline 14 & Wistar rats & Oral & $50 \%$ & $5 \mathrm{ml} / \mathrm{kg}$ & 4 weeks & (51) \\
\hline \multicolumn{7}{|c|}{ Lieber-DeCarli model } \\
\hline 1 & Sprague-Dawley rats & Oral & $6.7 \% \mathrm{v} / \mathrm{v}$ & Not available & 28 days & $(52)$ \\
\hline
\end{tabular}


Another animal used for studying alcoholic liver disease is guinea pigs (Cavia porcellus). In this study, the pigs were administered $4 \mathrm{~g} / \mathrm{kg}$ of $50 \%$ ethanol orally, and the duration of the treatment was 90 days (58). Guinea pigs metabolize alcohol similar to humans in several aspects, including an equal redox status of mitochondrial and cytosolic NAD/NADH system; a similar subcellular distribution of a critical enzyme of gluconeogenesis, phosphoenolpyruvate carboxykinase, between mitochondria and cytosol; similar activities of several essential enzymes of carbohydrate metabolism and ketogenesis. Thus, guinea pigs provide a better animal model for studying alcoholic hypoglycemia and alcoholic ketoacidosis (58-60). The zebrafish larva model has recently been developed and shows high sensitivity, bridging in vitro cell-based models and in vivo mammalian models (61-63).

\subsection{Animal Model of Alcoholic Liver Injury}

Ethanol could be administered both intraperitoneally and orally in one or multiple doses. Both routes of administration have been used by many laboratories to study the pathogenesis of the alcoholic liver disease. Table 1 shows that the oral administration is the most frequently used. This route can mimic how humans consume alcohol. According to the dose of ethanol and duration of treatment, there are several animal models: the acute ethanol-induced liver injury model, chronic ethanol-induced liver injury model, Lieber-DeCarli model, and Tsukamoto-French model. However, the studies we evaluated in this review used only the acute ethanol-induced liver injury model, chronic ethanolinduced liver injury model, and Lieber-DeCarli model.

\subsection{Acute Ethanol-Induced Liver Injury Model}

The oral route is the most frequently used in the acute ethanol-induced liver injury model. Only one study used the intraperitoneal route. $50 \%$ ethanol was used in both mice and rats. Ethanol doses in mice vary from 5 to 14 $\mathrm{ml} / \mathrm{kg}$ body weight, while, in rats, they vary from 5 to 18 $\mathrm{ml} / \mathrm{kg}$ body weight. Generally, the used doses in rats are 4-6 $\mathrm{g}$ ethanol/kg body weight (64).

Transaminase serum is a biochemical marker used in assessing liver functions. The study with the highest serum alanine transaminase (ALT) $(389.20 \%)$ levels used $12 \mathrm{~mL} / \mathrm{kg}$ body weight $50 \%$ ethanol (35), while the study with the highest serum aspartate transaminase (AST) (366.67\%) used the highest dose and concentration of ethanol $(18 \mathrm{~mL} / \mathrm{kg}$ body weight $56 \%$ ethanol) (32). Both studies used rats (Wistar and Sprague-Dawley rat) and used a relatively high dose of ethanol. However, high serum ALT levels are not always followed by elevation of serum AST. Serum ALT is a more specific parameter of liver damage because AST is found in different tissues, including the heart, brain, and skeletal muscles (65). Glutathione Stransferase alpha 1 (GSTA1) can be used as a biomarker in the acute ethanol-induced liver injury model. It can be detected at a low level during the early stage of acute hepatic injury. Furthermore, GSTA1 is a more sensitive and accurate indicator than ALT (26).

Liver sections of rats treated with acute ethanol administration showed mild histopathological alterations such as a disordered arrangement of hepatic cells, inflammatory cell infiltration, cavitation in hepatocytes, and necrosis. Rats experienced steatosis in only two studies.

\subsection{Chronic Ethanol-Induced Liver Injury Model}

The chronic ethanol-induced liver injury model is associated with a long period of excessive ethanol consumption. Several studies using the chronic ethanolinduced liver injury model were conducted. The highest ethanol dose was $10 \mathrm{ml} / \mathrm{kg}$ body weight with a concentration of $70 \%$. The study was conducted for 30 days resulting in elevating serum ALT and AST levels by $109.94 \%$ and $94.22 \%$, respectively (47).

A study that had the highest serum ALT and AST levels was conducted using a lower dose but with more prolonged treatment (three weeks) (48). Chronic ethanol consumption can promote the formation of hepatic steatosis - the early symptom of alcoholic liver disease. Studies (41) and (51) used methods that caused severe steatosis and abundant infiltrated inflammatory cells. All studies conducted using this model showed no fibrosis on liver morphology.

\subsection{Lieber-DeCarli Model}

At first, the Lieber-DeCarli model was developed to outrun the liver injury of the ethanol drinking model. In this model, the animal is given a diet that consists of protein, fat, carbohydrate, and fiber to imitate the clinical situation of heavy alcohol consumption in humans. However, this original formula has been developed with three variant diets: regular diet, low-fat diet, and high protein-content diet. The low-fat diet is used to study the effect of ethanol in minimized hepatic fat accumulation. The high protein diet is used to study conditions requiring high protein consumption, such as gestation and lactation (66).

Only one study used this model. A study conducted by (52) used the original Lieber-DeCarli liquid diet as the control diet and used an ethanol concentration of $6.7 \%(\mathrm{v} / \mathrm{v})$. ALT and AST serum levels increased mildly compared with those in the acute ethanol-induced liver injury model.

Lieber-DeCarli liquid diet was administered for 4 12 weeks. The Lieber-DeCarli diet model produces fatty liver, and metabolic tolerance and lesion beyond steatosis are rare. Although the ethanol in the drinking water model (oral) showed similar results, no fibrosis was present, and this model is considered more appropriate for studying the early stages of alcoholic liver diseases (67).

\section{Conclusion}

Rodents are more preferred for studying alcoholic liver diseases, and Wistar rats are the most frequently 
used. All studies conducted using rodents showed significant elevation of serum ALT and AST. Alterations in the histopathological analysis depend on the ethanol dose and duration of the treatment. Severe steatosis is shown in both chronic ethanol-induced liver injury and Lieber-DeCarli models. However, fibrosis remains undetected in all models.

\section{Authors' Contributions}

HDR was involved in data collection, drafting, writing, and revising the article. TH and RM conceptualized the idea and supervised and critically revised the article.

\section{References}

1. Hanson D. Historical evolution of alcohol consumption in society. Alcohol: science, policy and public health. 2013;3-12.

2. Bruha R, Dvorak K, Petrtyl J. Alcoholic liver disease. World J Hepatol. 2012 Mar 27;4(3):8190.

3. Scott S, Kaner E. Alcohol and public health: heavy drinking is a heavy price to pay for populations. $\mathbf{J}$ Public Health. 2014 Sep 1;36(3):396-8.

4. Mann RE, Smart RG, Govoni R. The epidemiology of alcoholic liver disease. Alcohol Res Health. 2003;27(3):209-19.

5. Orman ES, Odena G, Bataller R. Alcoholic liver disease: Pathogenesis, management, and novel targets for therapy. J Gastroenterol Hepatol. 2013;28(S1):77-84.

6. WHO. Alcohol [Internet]. 2018 [cited $2021 \mathrm{Jul}$ 26]. Available from: https://www.who.int/newsroom/fact-sheets/detail/alcohol

7. Asrani SK, Devarbhavi H, Eaton J, Kamath PS. Burden of liver diseases in the world. J Hepatol. 2019;70(1):151-71.

8. Marsano LS, Mendez C, Hill D, Barve S, Mcclain CJ. Diagnosis and treatment of alcoholic liver disease and its complications. Alcohol Res Health. 2003;27(3):247-56.

9. Barve A, Khan R, Marsano L, V Ravindra K, McClain C. Treatment of alcoholic liver disease. Ann Hepatol. 2008;7(1):5-15.

10. Sudeep HV, Venkatakrishna K, Sundeep K, Vasavi HS, Raj A, Chandrappa S, et al. Turcuron: A standardized bisacurone-rich turmeric rhizome extract for the prevention and treatment of hangover and alcohol-induced liver injury in rats. Pharmacognosy Magazine. 2020;16(70):263.

11. Liu Y, Wang J, Li L, Hu W, Qu Y, Ding Y, et al. Hepatoprotective Effects of Antrodia cinnamomea: The modulation of oxidative stress signaling in a mouse model of alcohol-induced acute liver injury. Oxid Med Cell Longev. 2017;2017:1-12.
12. Frazier TH, Stocker AM, Kershner NA, Marsano LS, McClain CJ. Treatment of alcoholic liver disease. Therap Adv Gastroenterol. 2011;4(1):6381.

13. Zhang A, Sun H, Wang X. Recent advances in natural products from plants for treatment of liver diseases. Eur J Med Chem. 2013;63:570-7.

14. AbouZid S, Ahmed OM. Silymarin Flavonolignans. In: Studies in Natural Products Chemistry [Internet]. Elsevier; 2013 [cited 2021 Jul 26]. p. 469-84. Available from: https://linkinghub.elsevier.com/retrieve/pii/B9780 44459603100014X

15. Mohs RC, Greig NH. Drug discovery and development: Role of basic biological research. Alzheimers Dementia. 2017;3(4):651-7.

16. Almeida Junior $\mathrm{S}$ de. In vivo methods for the evaluation of anti-inflammatory and antinoceptive potential. Brazilian Journal Of Pain [Internet]. 2019 [cited $2021 \mathrm{Jul}$ 27];2(4). Available from: https://www.scielo.br/scielo.php?script=sci_arttext \&pid $=$ S2595-

31922019000400386\&lng=en\&nrm=iso\&tlng=en

17. Esteves PJ, Abrantes J, Baldauf H-M, BenMohamed L, Chen Y, Christensen N, et al. The wide utility of rabbits as models of human diseases. Exp Mol Med. 2018;50(5):1-10.

18. Bryda EC. The Mighty Mouse: The impact of rodents on advances in biomedical research. Mo Med. 2013;110(3):207-11.

19. Buthet LR, Bietto FM, Castro JA, Castro GD. Metabolism of ethanol to acetaldehyde by rat uterine horn subcellular fractions. Hum Exp Toxicol. 2011;30(11):1785-94.

20. Owens AH, Marshall EK. The metabolism of ethyl alcohol in the rat. J Pharmacol Exp Ther. 1955;115(3):360-70.

21. Plapp BV, Leidal KG, Murch BP, Green DW. Contribution of liver alcohol dehydrogenase to metabolism of alcohols in rats. Chem Biol Interact. 2015;234:85-95.

22. Holmes RS, Duley JA, Algar EM, Mather PB, Rout UK. Biochemical and genetic studies on enzymes of alcohol metabolism: the mouse as a model organism for human studies. Alcohol Alcohol. 1986;21(1):41-56.

23. Rodd-Henricks ZA, McKinzie DL, Shaikh SR, Murphy JM, McBride WJ, Lumeng L, et al. Alcohol deprivation effect is prolonged in the alcohol Preferring $(\mathrm{P})$ rat after repeated deprivations. Alcoholism. 2000;24(1):8-16.

24. Villarín Pildaín L, Vengeliene V, Matthäus F. New measurement criteria for studying alcohol drinking and relapse in rodents. In Silico Pharmacol. 2013;1:13.

25. Vengeliene V, Siegmund S, Singer MV, Sinclair JD, Li TK, Spanagel R. A comparative study on alcohol-preferring rat lines: effects of deprivation 
and stress phases on voluntary alcohol intake. Alcoholism. 2003;27(7):1048-54.

26. Liu F-P, Ma X, Li M-M, Li Z, Han Q, Li R, et al. Hepatoprotective effects of Solanum nigrum against ethanol-induced injury in primary hepatocytes and mice with analysis of glutathione S-transferase A1. J Chinese Med Assoc. 2016;79(2):65-71.

27. Zhang L, Meng B, Li L, Wang Y, Zhang Y, Fang $\mathrm{X}$, et al. Boletus aereus protects against acute alcohol-induced liver damage in the C57BL/6 mouse via regulating the oxidative stress-mediated NF-кB pathway. Pharm Biol. 2020;58(1):905-14.

28. Jain NK, Singhai AK. Protective role of Beta vulgaris L. leaves extract and fractions on ethanolmediated hepatic toxicity. Acta Pol Pharm. 2012;69(5):945-50.

29. Jang S-H, Cho S-W, Yoon H-M, Jang K-J, Song C-H, Kim C-H. Hepatoprotective Evaluation of Ganoderma lucidum Pharmacopuncture: In vivo Studies of Ethanol-induced Acute Liver Injury. J Pharmacopuncture. 2014;17(3):16-24.

30. Yu Y, Tian Z-Q, Liang L, Yang X, Sheng D-D, Zeng J-X, et al. Babao Dan attenuates acute ethanol-induced liver injury via Nrf2 activation and autophagy. Cell Biosci. 2019;9:80.

31. Huang Q-H, Xu L-Q, Liu Y-H, Wu J-Z, Wu X, Lai X-P, et al. Polydatin Protects Rat Liver against Ethanol-Induced Injury: Involvement of CYP2E1/ROS/Nrf2 and TLR4/NF-кB p65 Pathway. Evid Based Complement Alternat Med. 2017;2017:7953850.

32. Tian Z, Jia H, Jin Y, Wang M, Kou J, Wang C, et al. Chrysanthemum extract attenuates hepatotoxicity via inhibiting oxidative stress in vivo and in vitro. Food Nutr Res. 2019;63.

33. Hao L, Xie Y, Wu G, Cheng A, Liu X, Zheng R, et al. Protective Effect of Hericium erinaceus on Alcohol Induced Hepatotoxicity in Mice. Evid Based Complement Alternat Med. 2015;2015:418023.

34. Lee SY, Ko KS. Effects of S-Adenosylmethionine and Its Combinations With Taurine and/or Betaine on Glutathione Homeostasis in Ethanol-induced Acute Hepatotoxicity. Journal of Cancer Prevention. 2016 Sep 1;21(3):164-72.

35. Iqbal S, Mujahid M, Kashif S, Khalid M, Badruddeen, Arif DrM, et al. Protection of hepatotoxicity using Spondias pinnata by prevention of ethanol-induced oxidative stress, DNA-damage and altered biochemical markers in Wistar rat. Integrative Medicine Research. 2016 May 1;5.

36. Zheng Y, Cui J, Chen AH, Zong ZM, Wei XY. Optimization of ultrasonic-microwave assisted extraction and hepatoprotective activities of polysaccharides from trametes orientalis. Molecules. 2019;24(1):147.

37. Jiang Z, Wang J, Xue H, Wang M, Jiang H, Liang $\mathrm{Y}$, et al. Protective effect of wild Corni fructus methanolic extract against acute alcoholic liver injury in mice. Redox report : communications in free radical research. 2016;22:1-8.

38. Pal S, Bhattacharjee A, Mukherjee S, Bhattacharya K, Mukherjee S, Khowala S. Effect of Alocasia indica Tuber Extract on Reducing Hepatotoxicity and Liver Apoptosis in Alcohol Intoxicated Rats. BioMed research international. 2014 May 29;2014:349074.

39. Lodhi P, Tandan N, Singh N, Kumar D, Kumar M. Camellia sinensis (L.) Kuntze Extract Ameliorates Chronic Ethanol-Induced Hepatotoxicity in Albino Rats. Evid Based Complement Alternat Med. 2014;2014:787153.

40. Amang AP, Kodji E, Mezui C, Baane MP, Siwe GT, Kuissu TM, et al. Hepatoprotective Effects of Aqueous Extract of Opilia celtidifolia (Opiliaceae) Leaves against Ethanol-Induced Liver Damage in Rats. Evid Based Complement Alternat Med. 2020;2020:6297475.

41. Zhou J, Zhang J, Wang C, Qu S, Zhu Y, Yang Z, et al. Açaí (Euterpe oleracea Mart.) attenuates alcohol-induced liver injury in rats by alleviating oxidative stress and inflammatory response. Exp Ther Med. 2018;15(1):166-72.

42. Panda V, Ashar H, Srinath S. Antioxidant and hepatoprotective effect of Garcinia indica fruit rind in ethanol-induced hepatic damage in rodents. Interdiscip Toxicol. 2012;5(4):207-13.

43. Lu C, Zhang F, Xu W, Wu X, Lian N, Jin H, et al. Curcumin attenuates ethanol-induced hepatic steatosis through modulating Nrf2/FXR signaling in hepatocytes. IUBMB Life. 2015;67(8):645-58.

44. Noorani AA, Kale MK. Pretreatment of Albino Rats with Methanolic Fruit Extract of Randia Dumetorum (L.) Protects against Alcohol Induced Liver Damage. Korean J Physiol Pharmacol. 2012;16(2):125-30.

45. Shukla I, Azmi L, Gupta SS, Upreti DK, Rao CV. Amelioration of anti-hepatotoxic effect by Lichen rangiferinus against alcohol induced liver damage in rats. J Ayurveda Integr Med. 2019;10(3):171-7.

46. Kim GJ, Song DH, Yoo HS, Chung KH, Lee KJ, An JH. Hederagenin supplementation alleviates the pro-inflammatory and apoptotic response to alcohol in rats. Nutrients. 2017;9(1):E41.

47. Chaphalkar R, Apte KG, Talekar Y, Ojha SK, Nandave M. Antioxidants of Phyllanthus emblica L. Bark Extract Provide Hepatoprotection against Ethanol-Induced Hepatic Damage: A Comparison with Silymarin. Oxid Med Cell Longev. 2017;2017:3876040.

48. Rejitha S, Prathibha P, Indira M. Nrf2-mediated antioxidant response by ethanolic extract of Sida cordifolia provides protection against alcoholinduced oxidative stress in liver by upregulation of glutathione metabolism. Redox Rep. 2015;20(2):75-80.

49. Prathibha P, Rejitha S, Harikrishnan R, Das SS, Abhilash PA, Indira M. Additive effect of alpha- 
tocopherol and ascorbic acid in combating ethanolinduced hepatic fibrosis. Redox Rep. 2013;18(1):36-46.

50. Pourbakhsh H, Taghiabadi E, Abnous K, Hariri A, Hosseini S, Hosseinzadeh H. Effect of Nigella sativa fixed oil on ethanol toxicity in rats. Iranian journal of basic medical sciences. 2014;17:102031.

51. Rezaee Khorasany A, Razavi M, Taghiabadi E, Tabatabaee Yazdy A, Hosseinzadeh H. Effect of crocin, an active saffron constituent, on ethanol toxicity in the rat: histopathological and biochemical studies. Iranian Journal of Basic Medical Sciences [Internet]. 2020 ;23(1).

52. Yoo J-H, Kang K, Yun JH, Kim MA, Nho CW. Crepidiastrum denticulatum extract protects the liver against chronic alcohol-induced damage and fat accumulation in rats. J Med Food. 2014;17(4):432-8.

53. Alderman JA, Sanny C, Gordon E, Lieber CS. Ethanol feeding can produce secondary alterations in aldehyde dehydrogenase isozymes. Alcohol. 1985;2(1):91-5.

54. Michoudet C, Baverel G. Metabolism of acetaldehyde in human and baboon renal cortex. Ethanol synthesis by isolated baboon kidneycortex tubules. FEBS Lett. 1987;216(1):113-7.

55. Nomura F, Pikkarainen PH, Jauhonen P, Arai M, Gordon ER, Baraona E, et al. Effect of ethanol administration on the metabolism of ethanol in baboons. J Pharmacol Exp Ther. 1983;227(1):7883.

56. French SW, Ruebner BH, Mezey E, Tamura T, Halsted $\mathrm{CH}$. Effect of chronic ethanol feeding on hepatic mitochondria in the monkey. Hepatology. 1983;3(1):34-40.

57. Rogers AE, Fox JG, Murphy JC. Ethanol and diet interactions in male rhesus monkeys. Drug Nutr Interact. 1981;1(1):3-14.

58. Abhilash PA, Harikrishnan R, Indira M. Ascorbic acid supplementation down-regulates the alcohol induced oxidative stress, hepatic stellate cell activation, cytotoxicity and mRNA levels of selected fibrotic genes in guinea pigs. Free Radic Res. 2012;46(2):204-13.

59. Hoet P, Buchet J-P, Sempoux C, Haufroid V, Rahier J, Lison D. Potentiation of 2,2-dichloro1,1,1-trifluoroethane (HCFC-123)-induced liver toxicity by ethanol in guinea-pigs. Arch Toxicol. 2002;76(12):707-14.

60. Zahlten RN, Nejtek ME, Jacobsen JC. Ethanol metabolism in guinea pig: ethanol oxidation and its effect on NAD/NADH ratios, oxygen consumption, and ketogenesis in isolated hepatocytes of fed and fasted animals. Arch Biochem Biophys. 1982;213(1):200-31.

61. Sukardi H, Chng HT, Chan ECY, Gong Z, Lam $\mathrm{SH}$. Zebrafish for drug toxicity screening: bridging the in vitro cell-based models and in vivo mammalian models. Expert Opin Drug Metab Toxicol. 2011;7(5):579-89.

62. Huang M, Xu J, Shin CH. Development of an ethanol-induced fibrotic liver model in zebrafish to study progenitor cell-mediated hepatocyte regeneration. J Vis Exp. 2016;(111):54002.

63. Podechard N, Chevanne M, Fernier M, Tête A, Collin A, Cassio D, et al. Zebrafish larva as a reliable model for in vivo assessment of membrane remodeling involvement in the hepatotoxicity of chemical agents. J Appl Toxicol. 2017;37(6):73246.

64. Mathews S, Xu M-J, Wang H, Bertola A, Gao B. Animal models of alcohol-induced liver disease: pathophysiology, translational relevance and challenges. American journal of physiology Gastrointestinal and liver physiology. 2014;306.

65. Dhillon A, Steadman RH. Liver diseases. anesthesia and uncommon diseases: Sixth Edition. 2012 Jan 1;162-214.

66. Lieber CS, DeCarli LM. The feeding of alcohol in liquid diets: two decades of applications and 1982 update. Alcohol Clin Exp Res. 1982;6(4):523-31.

67. Kim DH, Lee EM, Do SH, Jeong DH, Jeong KS. Changes of the cytoplasmic proteome in response to alcoholic hepatotoxicity in rats. Int J Mol Sci. 2015;16(8):18664-82. 